\title{
Telestroke for the Long-term Management of Risk Factors in Stroke Survivors
}

\author{
Joubert J22, Medeiros de Bustos E1, \\ Decavel P3, Chopard JL3, \\ Joubert LB ${ }^{4}$ and Moulin T ${ }^{1}$ \\ ${ }^{1}$ University of Franche-Comte \\ ${ }^{2}$ Royal Melbourne Hospital \\ ${ }^{3}$ University Hospital of Besancon \\ ${ }^{4}$ University of Melbourne \\ ${ }_{1,3}$ France \\ ${ }^{2.4}$ Australia
}

\section{Introduction}

Stroke is a major public health issue worldwide and, being the largest cause of chronic disability in adults, places a significant burden on health care systems. According to the World Health Organisation (WHO), around 15 million people each year suffer a stroke, and 5 million are left with a permanent disability . Over the past two decades, stroke has become an increasingly treatable disease with the development of evidence-based treatments such as tissue plasminogen activator (rt-PA) for the treatment of acute ischemic stroke and admission of patients to stroke units. This has led to a decrease in stroke mortality in developed countries and an increase in the number of survivors with impairment or disability. Stroke is an example of a largely preventable disease that presents acutely, with a short time window within which damage to the brain can be reduced. There is a high risk for residual disability which impacts significantly on society, the patients and their families . Stroke recurrence can lead to a progressive decline into dependency, subsequently placing a significant financial burden on society. In 2008, the indirect and direct costs of stroke in the United States were calculated at $\$ 65.5$ billion .

$87 \%$ of strokes are caused by cerebral infarction and are therefore amenable to a number of pre-stroke preventive strategies as well as thrombolytic therapy or intravascular clot retrieval strategies in the acute phase. The second major subtype of stroke, i.e. intracerebral parenchymal haemorrhage, is largely preventable through pre-stroke blood pressure control.

In this chapter, we will primarily discuss the current data regarding prevention and limitation of acute brain damage resulting from cerebral infarction, but will also consider other expanding areas in stroke care where telemedicine has a potential role. We will therefore examine the use of telestroke in stroke survivors after discharge from hospital, with particular emphasis on developed models of care and their applicability. 


\section{The prevalence of recurrent stroke}

In stroke survivors, the overall risk of recurrent stroke (fatal or nonfatal) is high (approximately 20\%) at 5 years . A recent study carried out in Perth, Australia, which aimed to determine the absolute frequency of first recurrent stroke and disability, as well as the relative frequency of recurrent stroke, demonstrated that over a 10-year follow-up period, the risk of first recurrent stroke is 6 times higher than the risk of first-ever stroke in the general population of the same age and sex. In addition, almost one half of survivors remain disabled, and one seventh require institutional care. The burden of stroke will continue to be a significant healthcare problem unless the incidence of not only first-ever, but also recurrent stroke and its disabling sequelae are reduced.

\subsection{Risk factor management}

In 1970, a landmark paper showed that hypertension was a major risk factor for all types of stroke. It has since been confirmed in more recent studies that high blood pressure is indeed a powerful determinant of risk for both ischaemic stroke and intracranial haemorrhage .

Other major risk factors for stroke such as obesity, smoking, embolic heart disease and diabetes mellitus are well recognised .

The potential for recurrent stroke can be substantially reduced by effective management of these risk factors, and the development of systems that can enhance the prevention of stroke recurrence is an important priority and challenge in both the developed and developing worlds. The same few major risk factors account for many of the leading chronic health problems worldwide. Nevertheless they remain on the increase and are poorly managed in the majority of affected individuals. According to the WHO, the number of overweight people worldwide will increase to 2.3 billion by 2015, and more than 700 million will be obese . In parallel, more than 200 million people have diabetes and the WHO projects that the prevalence will double between 2005 and 2030 .

\subsection{Importance of preventive strategies}

The main challenge involves reducing the prevalence of recurrent stroke, particularly in remote and rural areas, through: i) effective strategies for the management of risk factors; and ii) educating the target population (essentially stroke victims and carers/family members) to increase awareness of risk factors and preventive strategies.

Prevention is the most effective way of reducing the burden of recurrent stroke on society . Although it has been shown that effective long-term risk factor management can reduce the risk of recurrent stroke by around $70-80 \%$ through the implementation of simple best practice recommendations, secondary prevention measures remain frequently suboptimally implemented in stroke survivors. Indeed, in an editorial in the journal Stroke, Hachinski specified that despite the worldwide increase in stroke occurrence as a result of several well-known risk factors, these factors are often poorly managed. 'Therapeutic inertia' is common at primary care level and there is a high rate of medication discontinuation in stroke survivors after discharge. This was highlighted in a French urban study, which served to emphasise that there is currently a gap between recommendations and implementation of best practice management of risk factors, even in Western Europe. A large Swedish population-based cohort study involving 28,449 participants revealed an increased hypertension rate $(79.4 \%)$ in people with a history of previous stroke 7.5 years after enrolment. Only half were taking anti-hypertensive medication and only $11.5 \%$ 
achieved a blood pressure reading $<140 / 90 \mathrm{~mm} \mathrm{Hg}$. In addition, the majority of stroke survivors with hypercholesterolaemia were not prescribed lipid lowering medication, and only $38 \%$ received antithrombotics. One third of patients were still smoking, two thirds were obese and the overall calculated stroke risk was found to be significantly higher in stroke survivors than in people without stroke. A randomized controlled trial of an outreach nursing support programme for recently discharged stroke patients in the Netherlands showed that quality of life deteriorated significantly in the post-discharge period and that about $50 \%$ of stroke survivors were dissatisfied with the care provided after discharge. Canadian data suggests that although many hospitals have focused their attention on acute service provision, ongoing patient support related to secondary prevention has not been adequately addressed. Similarly, a review of hospital-based stroke services in North Carolina showed that, over a 5-year period, virtually no progress had been made in hospital programmes for stroke prevention .

All this would argue that secondary prevention and long-term management of risk factors is a neglected area that requires urgent attention and has clearly defied efforts, even in the developed world, for optimal implementation.

\subsection{Barriers to effective risk factor management}

Globally, the majority of strokes occur in rural areas where there is often a lack of stroke services. In these areas, stroke care is often fragmented and does not adhere to recommended guidelines. This, together with the geographical barriers that are associated with a general attenuation of access to healthcare resources and the paucity of stroke experts frequently leads to an inequitable distribution of resources and limited access to preventive strategies and evidence-based care. On a global scale it would seem that not only are vascular risk factors on the increase, but they are also not systematically recognised or diagnosed. The results of a recent longitudinal cohort study in the United States, for example, revealed high rates of undiagnosed hypertension and diabetes among stroke survivors .

The problem is further compounded by the lack of public awareness and knowledge of stroke risk factors and preventive strategies. A recent study of stroke survivors found that only 60.5 percent were able to identify one stroke risk factor and only $55.3 \%$ were able to identify one stroke warning sign . Similarly, a study of 286 consecutive patients who were attending a stroke outpatient clinic in Switzerland for the first time 3 months after being discharged from hospital for a first stroke, reported that despite an improvement in hospital treatment, cerebrovascular risk factor control was not optimal . This may have been partly related to the patients' awareness and knowledge. Older patients and patients with excellent recovery were at particular risk of recurrent stroke due to poor awareness of vascular risk factor control. Better strategies are clearly needed to help stroke survivors recognise and play a part in the control of vascular risk factors so as to improve the prevention rate of recurrent stroke.

\section{Telemedicine and its potentials}

\subsection{Background to telemedicine and telestroke}

Telemedicine has been defined, simply, as the delivery of healthcare services to the underserved, employing telecommunication . A more extensive definition is "the process by which electronic, visual and audio communications are used to provide diagnostic and 
consultation support to practitioners at distant sites, assist in or directly deliver medical care to patients at distant sites, and enhance the skills and knowledge of distant medical care providers . Telemedicine, as a distance communication tool, was first attempted in radiology 50 years ago and subsequently in psychiatry. Since 1999 there has been a gradual increase in the number of telemedicine programmes and more recently a growing interest in its use in stroke, mainly in facilitating thrombolysis, but also in establishing diagnoses and guiding treatment options .

"Telestroke" refers to the application of telemedicine to stroke care. This is a new application of existing technology in the care of stroke patients. Evidence suggests that telestroke is beneficial where immediate access to regular stroke expertise is not available . Thus it may help to provide stroke care to patients in remote regions and smaller urban hospitals without stroke expertise and to extend clinical research into a broader global community, thereby furthering the goal of establishing universal access to care at all levels, regardless of geographical location or hospital facilities .

Although telemedicine has until now mainly focused on the area of thrombolysis in the acute stage, it has the potential to address the remaining stages of the stroke victim's journey following discharge from hospital or in the rehabilitation setting. Attention at all these levels can substantially lower the net cost of recurrent stroke to society through reduction of lost productivity, nursing home costs and rehabilitation .

Demonstration projects have proven the feasibility of telestroke and suggested its potential to facilitate access to specialist stroke expertise in hospitals without access to specialist clinicians. In particular, the use of this technology may promote implementation of best practice management of vascular risk factors in stroke survivors after discharge. One of the main drivers has been technological advancement, such as the digitisation and compression of data permitting the rapid transfer of images. This can now be linked to systems of care that integrate person-to-person contact (which have already been developed in the areas of psychiatry and social work), thus providing a structure which delivers care to underserved areas by combining state-of-the-art technology providing the face-to-face contact that patients still need.

\subsection{Review of the relevant literature on telestroke for stroke survivors \\ 3.2.1 Methodology}

In 2009 we reviewed evidence of telestroke support in stroke survivors discharged from hospital. The Canadian Agency for Drugs and Technologies in Health (CADTH) reported on a systematic review of 5 bibliographic databases examining telestroke from 1966 to December 2006. 863 citations were identified, and from these, 35 potentially relevant reports yielding 22 studies originating from the US, Germany, Canada, China, the Netherlands, Italy and Finland. Using this as a base, we further searched the literature which involved searching the relevant primary and secondary databases for all papers (peer-reviewed where possible) that covered stroke and telemedicine in stroke survivors. We combined MeSH searching with (relevant) 'words anywhere' searching. The results were examined via abstracts; if no abstracts were available, full text-versions were sighted. Selected papers were obtained in full-text version and additional relevant papers were searched and reviewed as needed from references cited in papers. The searches were limited to the period from 1998 to 2009 and no restriction was placed on study designs. Primary databases searched were Medline EMBASE, CINAHL, AMED and PsycInfo. We also searched the Cochrane databases. The main subject terms used were telemedicine, telephone, electronic mail, 
videoconferencing and stroke. Additional subject terms searched were patient discharge and hospitals, and other relevant terms searched were telestroke, telehealth, primarysecondary and post-acute, patient surveillance, patient monitoring, and risk assessment. From the primary sources we found 82 papers in total of which 72 were retained for examination. From Cochrane, one systematic review was found. The final studies included can be seen in Table 1. In 8 studies the telemedicine focus was not on rehabilitation; of these six were RCTs. Telerehabilitation was the focus of 12 other studies, only one being an RCT. A total of 28 studies evaluated a variety of measures in stroke patients.

\begin{tabular}{|c|c|c|c|c|}
\hline Study Type & Reference & $\begin{array}{l}\text { Telemedicine } \\
\text { Intervention }\end{array}$ & Target Groups & $\begin{array}{l}\text { Health } \\
\text { Professional } \\
\text { Involved }\end{array}$ \\
\hline RCT & $\begin{array}{l}\text { Mayo NE, et } \\
\text { al, } 2008\end{array}$ & $\begin{array}{l}\text { Telephone calls by } \\
\text { nursing care } \\
\text { coordinator over } 6 \\
\text { weeks after } \\
\text { discharge. }\end{array}$ & $\begin{array}{l}190 \text { stroke patients } \\
n=96 \text { intervention } \\
n=94 \text { controls }\end{array}$ & $\begin{array}{l}\text { Nurse Care } \\
\text { Manager, } \\
\text { Patient's Local } \\
\text { Physician }\end{array}$ \\
\hline RCT & Joubert 2008 & $\begin{array}{l}\text { Integrated model of } \\
\text { care (ICARUSS) } \\
\text { Risk factor } \\
\text { management }\end{array}$ & $\begin{array}{l}91 \text { stroke survivors } \\
\text { and } 95 \text { controls }\end{array}$ & $\begin{array}{l}\text { Care-Coordinator } \\
\text { and Patient's } \\
\text { General } \\
\text { Practitioner }\end{array}$ \\
\hline RCT & Joubert 2008 & $\begin{array}{l}\text { Integrated model of } \\
\text { care (ICARUSS) } \\
\text { Screening for } \\
\text { depression (PHQ9) }\end{array}$ & $\begin{array}{l}91 \text { stroke survivors } \\
\text { and } 95 \text { controls }\end{array}$ & $\begin{array}{l}\text { Care-Coordinator } \\
\text { and Patient's } \\
\text { General } \\
\text { Practitioner }\end{array}$ \\
\hline $\mathrm{RCT}$ & $\begin{array}{l}\text { Grant JS et } \\
\text { al, } 2002\end{array}$ & $\begin{array}{l}\text { Telephone contact } \\
\text { strategy for } \\
\text { problem- solving } \\
\text { therapy over } 18 \\
\text { months. }\end{array}$ & $\begin{array}{l}74 \text { Stroke Survivors } \\
\text { and Caregivers in } \\
\text { three groups: } \\
\text { treatment, sham and } \\
\text { control }\end{array}$ & Research Nurse \\
\hline $\mathrm{RCT}$ & $\begin{array}{l}\text { Boter H, } \\
2004\end{array}$ & $\begin{array}{l}\text { Outreach care } \\
\text { included } 3 \text { telephone } \\
\text { calls and a home } \\
\text { visit within } 5 \\
\text { months of discharge. }\end{array}$ & $\begin{array}{l}\text { Randomized } 536 \\
\text { stroke patients; } 263 \\
\text { (with } 211 \text { carers to } \\
\text { standard care plus } \\
\text { outreach care and } 273 \\
\text { (with } 230 \text { carers) to } \\
\text { standard care only. }\end{array}$ & 13 Stroke nurses \\
\hline $\begin{array}{l}\text { Qualitative } \\
\text { study }\end{array}$ & Pierce 2004 & $\begin{array}{l}\text { Internet based } \\
\text { education and } \\
\text { support }\end{array}$ & $\begin{array}{l}9 \text { Caregivers of } \\
\text { patients with stroke } \\
\text { using Caring Web }\end{array}$ & Nurse \\
\hline $\begin{array}{l}\text { Descriptive } \\
\text { Study }\end{array}$ & $\begin{array}{l}\text { Buckley KM, } \\
\text { Tran BQ, } \\
\text { Prandoni } \\
\text { CM, 2004 }\end{array}$ & $\begin{array}{l}\text { Tele-health nurses } \\
\text { use videophones to } \\
\text { contact caregivers }\end{array}$ & $\begin{array}{l}21 \text { family caregivers of } \\
\text { stroke patients }\end{array}$ & $\begin{array}{l}\text { Nurse } \\
\text { Investigator }\end{array}$ \\
\hline
\end{tabular}

Table 1. Non-Rehabilitation Studies using Telestroke in Stroke Survivors 


\subsubsection{Post-discharge telestroke models}

Of the non-rehabilitation telestroke studies involving stroke survivors, one was an Internet educational model, there was one passive case management model, one was a videophonesupported educational model, one was a nursing outreach telephone support model, one was an interactive telephone support model and one was a telephone/ Internet-based EDC integrated care model. Three involved caregivers only, one involved patients and general practitioners, one involved patients and caregivers, and one involved stroke specialists, patients, caregivers and primary care physicians. There were 21 studies (one being an RCT) describing the application of telestroke in rehabilitation. Most of the studies have described the use of technology solutions, principally to support rehabilitation activities .

The HESTIA Study Group instituted a programme of outreach care consisting of 3 telephone calls and one home visit by nursing staff within the 5 months after discharge. The target population was patients and carers, and the intervention was general support, education and advice. General practitioners were indirectly involved, in that nurses advised contact with the general practitioner where appropriate. Quality of life according to the Short Form 36 (SF 36) and dissatisfaction with care were assessed at 6 months. Apart from improved scores on the SF-36 domain 'Role Emotional' no difference was found between patients receiving outreach nursing stroke care and controls.

In the study by Pierce at al. an Internet-based education and support intervention was directed at rural caregivers. Outcomes in this qualitative study were satisfaction with the intervention and an exploration of caregivers' experience. Of the nine caregivers studied, all indicated satisfaction with the "Caring-Web" and eight agreed or strongly agreed that the tool was needed.

An RCT evaluating the effect of telephone intervention with family caregivers of stroke survivors, involving a social problem-solving therapy over a period of 18 months, yielded significantly positive results on a variety of measures such as problem-solving skills, social functioning, caregiver depression, measures of vitality, role limitations related to emotional issues and caregiver preparedness. The target population was caregivers, and intervention was weekly or bi-weekly telephone calls. The three groups were tested-intervention, sham and control.

In a descriptive study, targeting family caregivers of stroke patients, Buckley et al. used videophones to provide education and support and to assess patients and monitor progress. They studied the factors that influenced receptiveness for the use of this tool. The telehealth calls were made weekly and the duration of the intervention was 5 weeks.

Mayo et al. evaluated the effect of passive case management over a period of 6 weeks after discharge of stroke patients from hospital. The telestroke intervention was telephone contact and involved surveillance, information exchange, medication management, health system guidance, active listening, family support, teaching and risk identification. The target populations in this RCT was the stroke patients and their general practitioners. There was no difference between patients exposed to usual post-discharge management and this intervention regarding health-related quality of life, reduction of health services utilisation or stroke impact.

Moulin et al. have reported on the emergency neurology network in Franche-Comté (RUNFC), which monitors stroke victims over a five-year period following discharge. A nurse from the network maintains regular contact with the patients and organizes a consultation with a neurologist if a problem is detected. The patient's GP is also kept informed at all times. Since 2003, 2,600 stroke victims have been followed up within the network and $20 \%$ 
have required action to be taken by the network at least once. The survival rate of discharged patients at 18 months has risen from 87\% between 1987 and 1994, to $94 \%$ between 2003 and 2006. For patients in the network, the stroke recurrence rate at 18 months has also increased from 4.8\% between 1998 and 2002, to 2.6\% between 2003 and 2007 . RUNFC illustrates the usefulness of telemedicine for stroke survivors and the need to develop it further throughout France. Furthermore, in the long-term, the network has significantly reduced the stroke mortality rate and the number of recurrences, and has considerably improved the quality of life of patients in the network.

Joubert et al. examined the effect of a telemedicine intervention on both vascular risk factor management and depressive symptoms in the ICARUSS study. In this RCT, the intervention was telephone contact with patients and carers, and bi-directional information sharing between coordinator, patient and general practitioner using telephone and facsimile, coupled with data management, surveillance and response through a web-based EDC. Telephone contact between stroke specialist and primary care physician was maintained by telephone. The target populations were patients, carers and general practitioners. In this study, the pilot results were supportive of this simple telestroke model in that there was a significant improvement in a variety of outcome measures, such as optimal management of risk factors, BMI, physical activity, and disability as measured by modified Rankin score (mRS) in patients exposed to the telestroke intervention compared to usual care. Moreover, depressive symptoms were significantly reduced in the telestroke group. The protocols for the ICARUSS model are diagrammatically depicted in figures 1 and 2. The initial results from the pilot study have resulted in the multicentre Australian Study using the adapted ICARUSS model of care in urban stroke patients. As a result of the experience accrued from the ICARUSS study, important role players in an effective telestroke model have been identified. Moreover, the implementation of telestroke at various stages of the stroke survivor's journey has been clarified.

\subsubsection{Major role players in telestroke}

\section{i) Caregivers}

About $80 \%$ of stroke survivors are reliant on family caregivers for emotional and physical support, ranging from assisting with activities of daily living to arranging and escorting to medical appointments. Caregivers are often elderly, and often frequently infirm themselves. Caregiver failure or collapse is more frequently a cause for stroke survivor institutionalisation than is commonly realised. If the carer can be 'enrolled' and supported as a member of the team, there is an increased likelihood that the stroke survivor will remain in the community.

The Internet-based support study by Pierce et al. highlights the need of caregivers for emotional and social support and the general acceptance of a telestroke support system. Pilot work had indicated that a major issue identified by caregivers was the low level of knowledge about stroke in general, which their Internet-based study attempted to rectify. Important issues of acceptance by caregivers was emphasised in the study of Buckley et al. who found that for some carers, a technological challenge constituted only an extra burden. Some caregivers only wanted simple telephone support. In this study, it was evident that the nurse's support was paramount.

Assessment of caregivers' needs and limitations is important. Their level of technical competence, fear of intrusion into their privacy and desire for inclusion into a telestroke system all need to be evaluated. 


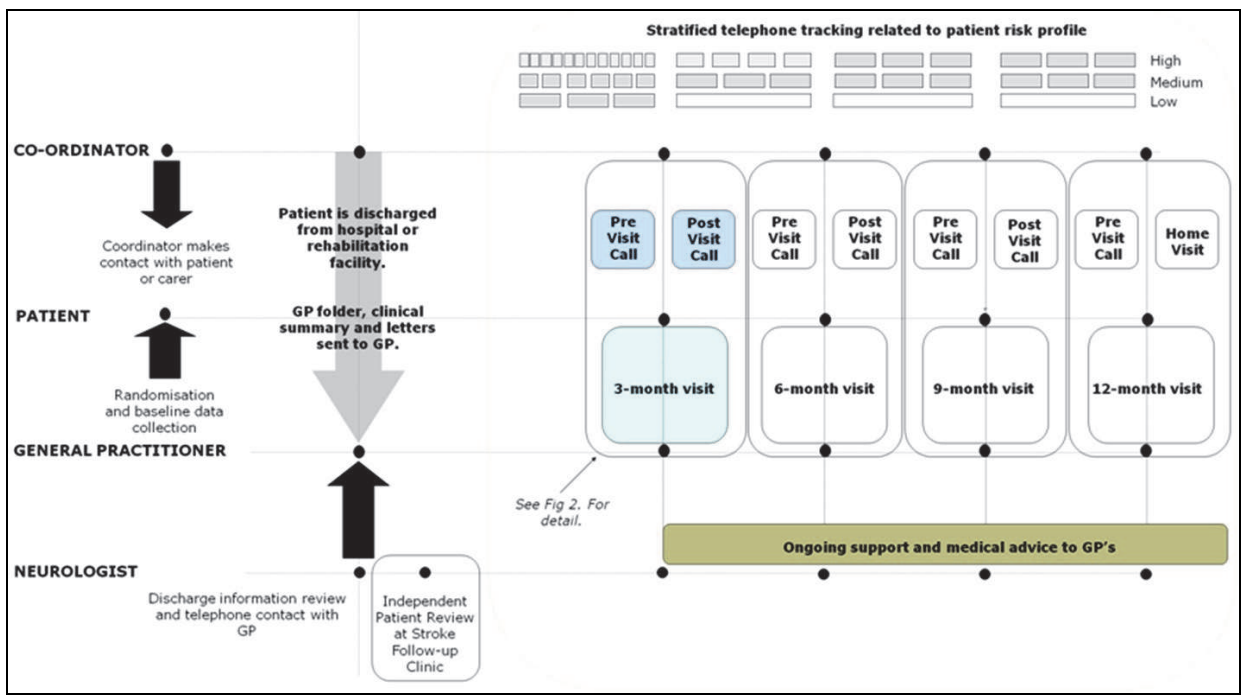

Fig. 1. Diagrammatic representation of telestroke process (ICARUSS protocol)

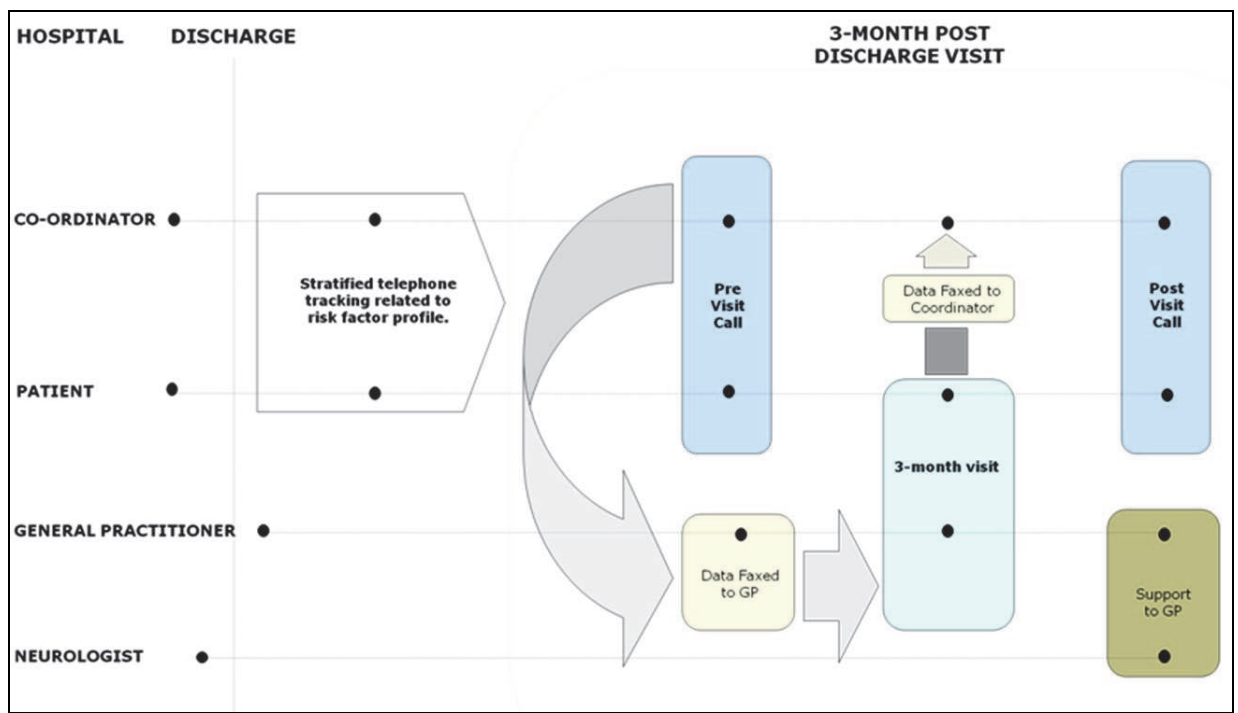

Fig. 2. Three-monthly Telestroke cycle of communication between coordinator, patient, caregiver and general primary care physician illustrating pre- and post general practice telecommunication (ICARUSS protocol)

Often overlooked issues include the functional ability of the caregiver, the amount of time able to be provided by the caregiver, the number of individuals sharing the burden, and involvement of the caregiver in management planning prior to discharge. The need for a flexible approach to telephone contact with caregivers has been emphasised in several 
studies. These studies stress that there is an unmet need in caregivers, and that although the solution is probably not simple, further research is required in this area.

The multicentre RCT in the Netherlands did not show evidence of either improving quality of life or lessening dissatisfaction with care. However, the study was of short duration with a low level of intervention, and a deliberately passive, but supportive and advisory role. Thirteen stroke nurses were employed for intervention in 263 stroke survivors. The Australian study, ICARUSS, differed in that one nurse coordinator supported over 90 patients for a period of one year. Similar to the Dutch study, a negative result was obtained in the study by Mayo et al. where the intervention was deliberately passive case management. In the study by Grant et al. , the problem-solving partnership resulted in significant improvement over many domains, as in the ICARUSS study.

\section{ii) Stroke survivors}

There is now evidence from the ICARUSS study that an integrated telestroke model can result in significantly improved risk factor management, as well as decreased levels of poststroke depressive symptoms . Despite the published importance of implementing best practice management principles, this is the only telestroke study that has addressed risk factor management directly and shown results in an RCT.

\section{iii) Medical professionals}

There are different roles to consider for primary care physicians and specialists in stroke services. In the study by Boter et al. , patients and carers were advised to seek help from primary care physicians when necessary. The contact and coordination with primary care physicians was more direct and active in the study by Mayo et al . Neither supported the general practitioner in risk factor management. In the Australian ICARUSS model, there is bi-directional information sharing regarding risk factor status of stroke survivors between the coordinator, specialist stroke services and primary care physician . Determined reaction to persistently abnormal values is an integral part of the model. The telephone support from the specialist physician to the primary care physician is part of the "shared care" component. In ICARUSS, screening for symptoms of depression is performed on a threemonthly basis and the results are faxed to the primary care physician. ICARUSS is an example of a telestroke model that maintains specialist involvement in the long-term. The immediate, real-time specialist support to the primary care physician provides the "contemporaneous sharing of responsibility" between primary care physicians and specialists, which is the element of shared care.

\section{iv) Coordinators}

The coordinator plays a key role in all the telestroke models for stroke survivors described above. In some, the role is passive, while in others the interaction is more active. The coordinator plays a part in problem-solving, education, surveillance and reaction, as well as psychological and social support. In the ICARUSS model, the coordinator provides the link between patient, caregiver, primary care physician and specialist stroke services.

\subsubsection{Telestroke support management services}

To date, the limited availability and acceptance of past Information and Communication Technology ( ICT) possibilities has limited the possible support options. At this stage, it is 
now possible to explore what Telestroke Support Management Services are available and appropriate as an adjunct to human contact, and in combination with some of the current telemedicine services outlined in Table 2. Any new technology should viewed as an advance on existing systems and compared rigorously in terms of cost-effectiveness as well as efficacy .

\section{i) Technology Options for Telestroke}

Across the different studies, a range of technology options have been used including telephone, facsimile, email, videoconferencing, and internet-based communication, which may be generic or personalized. Simple telephone contact has been shown to be useful in different situations, such as giving practical problem-solving advice to caregivers. Moreover, the contact has been useful in reducing stress. Telephone interviews have been shown to be reliable in the application of a variety of assessment and measuring tools, such as the Stroke Impact Scale (SIS) and proven reliable for the evaluation of disability and cognitive function in community outpatients. Telephone administration of the Patient Health Questionnaire (PHQ9) has also been validated in stroke patients. This instrument has demonstrated reliability as a screening tool for Post Stroke Depression. There is a need to determine the best modality to achieve the requisite goal in stroke survivors. These goals may be risk factor modification, patient and carer education, detection and management of post-stroke depression, carer support, strategy implementation, rehabilitation or simple surveillance of health service usage. Different modalities may be appropriate for different goals; simple telephone calls may suffice for patient and carer education or support, whereas a tele-rehabilitation programme may require videoconferencing, as would a psychiatric intervention for depression.

\begin{tabular}{|c|c|c|c|c|c|}
\hline \multicolumn{6}{|c|}{ TELESTROKE SERVICES } \\
\hline $\begin{array}{l}\text { Care Coordi } \\
\text { Secondary Stro }\end{array}$ & $\begin{array}{l}\text { lation and } \\
\text { e Prevention }\end{array}$ & Other & elemedicine $\mathrm{Fu}$ & Inctions & $\begin{array}{c}\text { Tele- } \\
\text { Rehabilitation }\end{array}$ \\
\hline $\begin{array}{l}\text { Carer Support } \\
\text { and Problem- } \\
\text { Solving }\end{array}$ & $\begin{array}{l}\text { Risk Factor } \\
\text { Management }\end{array}$ & $\begin{array}{c}\text { Emergency } \\
\text { Response }\end{array}$ & $\begin{array}{c}\text { Health } \\
\text { Information } \\
\text { and Education }\end{array}$ & $\begin{array}{l}\text { Medication } \\
\text { Compliance }\end{array}$ & $\begin{array}{c}\text { Remote } \\
\text { assessment and } \\
\text { therapy }\end{array}$ \\
\hline
\end{tabular}

Table 2.Overview of Telestroke potential

It is unlikely and undesirable that single solutions for different scenarios can be developed to meet the above telestroke service needs. Functional requirements need to be analysed and all available options considered. Although the literature reveals an interest in experimenting with new ICT from video conferencing and Internet web-cams, to virtual reality haptic workbenches, most ICT studies have relied on the telephone to study post-acute stroke survivor needs. Many of the ongoing assessment tools could potentially be integrated into handheld devices where audio and visual evidence could be directly captured.

Some studies have indicated that technology choices are limited to those acceptable to the survivors and/or their carers. Perhaps more important is the fact that the spectrum of ICT options is expanding rapidly, while costs are decreasing. However, deployment of these options is not uniformly available across all geographical and demographic users. For example, fibre optic cable is not yet as ubiquitous as copper networks and 3G intelligent mobile phone networks do not have the same coverage as GSM. 


\section{ii) Care Coordinator Requirements}

A missing systems requirement in the design of telestroke services is the functional requirement for implementation of the care coordinator role. Solutions adopted will depend on a number of factors such as the capture area of the services, remoteness of care and health provider locations, and the number of survivors involved - in other words, the caseload. It is expected that caseloads of over 80 stroke survivors would need a full time care coordinator, and their productivity would depend on the support systems available . The coordinator requirements are outlined in Table 3.

\begin{tabular}{|c|c|c|c|c|}
\hline $\begin{array}{l}\text { Telestroke } \\
\text { Modality }\end{array}$ & Costs & $\begin{array}{l}\text { CC to CR/ICG } \\
\text { Operational Issues }\end{array}$ & $\begin{array}{l}\text { CC to GP / } \\
\text { Specialist and/or } \\
\text { Hospital ED }\end{array}$ & Special Issues \\
\hline $\begin{array}{l}\text { Telephone } \\
\text { contact }\end{array}$ & Inexpensive & $\begin{array}{l}\text { Reliance on Phone } \\
\text { contacting limits case } \\
\text { load for CC. Ubiquitous } \\
\text { and } \\
\text { Saves Travel } \\
\text { Validated for several } \\
\text { assessments. }\end{array}$ & \begin{tabular}{|l|} 
Generally effective \\
Gives personal \\
contact. Non- \\
threatening to \\
elderly
\end{tabular} & $\begin{array}{l}\text { Note-taking of } \\
\text { interactions }\end{array}$ \\
\hline Facsimile & Inexpensive & Ubiquitous & $\begin{array}{l}\text { Generally effective. } \\
\text { Specified usage } \\
\end{array}$ & $\begin{array}{l}\begin{array}{l}\text { Storage } \\
\text { needed }\end{array} \\
\end{array}$ \\
\hline $\begin{array}{l}\text { Video- } \\
\text { conferencing } \\
\text { for visual } \\
\text { contact }\end{array}$ & $\begin{array}{l}\text { As for ICG; saves } \\
\text { travel. } \\
\text { Initial Setup can be } \\
\text { costly and is time- } \\
\text { consuming if used } \\
\text { frequently. }\end{array}$ & $\begin{array}{l}\text { Not readily available at } \\
\text { home. } \\
\text { Skype and webcam is } \\
\text { possible. }\end{array}$ & $\begin{array}{l}\text { Can be useful for } \\
\text { case referral } \\
\text { conferences }\end{array}$ & $\begin{array}{l}\text { Effort } \\
\text { required to } \\
\text { arrange; visit } \\
\text { may be more } \\
\text { effective }\end{array}$ \\
\hline $\begin{array}{l}\text { Internet } \\
\text { Contact }\end{array}$ & $\begin{array}{l}\text { Medium to high } \\
\text { costs to setup } \\
\text { computer, modem } \\
\text { and broadband } \\
\text { services }\end{array}$ & $\begin{array}{l}\text { Most efficient use of CC } \\
\text { time for data collection, } \\
\text { but not effective for } \\
\text { human interaction. } \\
\text { Elderly may have usage } \\
\text { barrier }\end{array}$ & $\begin{array}{l}\text { Can be useful for } \\
\text { sharing electronic } \\
\text { records and } \\
\text { reports }\end{array}$ & $\begin{array}{l}\text { Privacy and } \\
\text { data security } \\
\text { obligations }\end{array}$ \\
\hline Web Page & $\begin{array}{l}\text { Costly to set up and } \\
\text { resources needed to } \\
\text { maintain content }\end{array}$ & $\begin{array}{l}\text { Provides a } 24 / 7 \\
\text { resource to ICG/CR on } \\
\text { more frequent types of } \\
\text { info needs. Elderly may } \\
\text { have usage barrier }\end{array}$ & $\begin{array}{l}\text { Enables links to } \\
\text { service provider } \\
\text { organisations of } \\
\text { relevance to users }\end{array}$ & \begin{tabular}{|l|} 
Needs \\
updating \\
regularly to be \\
relevant; users \\
may need a \\
secure log-on \\
\end{tabular} \\
\hline $\begin{array}{l}\text { Health } \\
\text { Records } 1\end{array}$ & $\begin{array}{l}\text { Initial filling-in on } \\
\text { paper is fast and } \\
\text { low cost if well } \\
\text { designed }\end{array}$ & $\begin{array}{l}\text { An effective system is } \\
\text { required that meets } \\
\text { medical authority } \\
\text { standards. }\end{array}$ & $\begin{array}{l}\text { Need to be able to } \\
\text { share with } \\
\text { appropriate third } \\
\text { parties }\end{array}$ & $\begin{array}{l}\text { Security and } \\
\text { privacy } \\
\text { requirements; } \\
\text { long-term } \\
\text { storage } \\
\end{array}$ \\
\hline $\begin{array}{l}\text { Contact } \\
\text { Database } 2\end{array}$ & $\begin{array}{l}\text { Software is } \\
\text { available for this } \\
\text { function; desirable } \\
\text { to integrate with } \\
\text { EDS }\end{array}$ & $\begin{array}{l}\text { Essential for efficient } \\
\text { interactions }\end{array}$ & $\begin{array}{l}\text { Essential for } \\
\text { efficient } \\
\text { interactions }\end{array}$ & $\begin{array}{l}\text { Needs to } \\
\text { portable }\end{array}$ \\
\hline
\end{tabular}




\begin{tabular}{|l|l|l|l|l|}
\hline $\begin{array}{l}\text { Electronic } \\
\text { Documents } \\
\text { System }{ }^{3}\end{array}$ & $\begin{array}{l}\text { Can be expensive } \\
\text { and needs tailoring } \\
\text { for CC needs }\end{array}$ & $\begin{array}{l}\text { Effective for data } \\
\text { searching, studies and } \\
\text { archiving. }\end{array}$ & $\begin{array}{l}\text { Assists efficient } \\
\text { support for } \\
\text { hospitals, GPs and } \\
\text { specialists }\end{array}$ & $\begin{array}{l}\text { Secure } \\
\text { archiving of } \\
\text { data is } \\
\text { essential }\end{array}$ \\
\hline
\end{tabular}

CC: Care Coordinator; CR: Care Receiver / Stroke Survivor; ICG: Informal Care Giver; GP: General Practitioner (of CR); ED: Emergency Department

${ }^{1}$ These may be proformas or other reports handled in paper form.

${ }^{2}$ For tracking client interactions - planned and completed.

${ }^{3}$ For managing all documents electronically - paper is scanned

Table 3. Technology Options for Care Coordinator (CC)

\subsection{Further potential and possible limitations of telestroke for stroke survivors}

Telestroke programmes should address the post-discharge management of stroke survivors and the needs of caregivers. They should facilitate risk factor and other areas of medical management by the primary care physician (traditional general practitioner or clinic-based physician). Telestroke should also counteract the effects of isolation and limited access to specialist services in rural areas.

\subsubsection{Desirable functional requirements for a telestroke model}

Ideally, in a comprehensive telemedicine model a variety of items related to medical management, process, quality control and outcomes should be measured. These are shown in the Box. Of particular importance is the monitoring of vascular risk factors for the reduction of recurrent vascular events, primarily stroke - e.g. blood pressure, cholesterol, anticoagulation and blood sugar. Compliance with medication and surveillance of laboratory tests can be readily coordinated in a telestroke model.

The literature has suggested that there are a range of telestroke services that should now be considered to meet the wider needs of post-acute stroke survivors and the integrated care requirements:

- Telestroke model should facilitate knowledge transfer, particularly in relation to education and best practice recommendations for risk factor management .

- The system should provide, support and monitor clear management plans for secondary stroke prevention .

- $\quad$ There should be regular survey methods applicable to telemedicine of patient, carer and health provider satisfaction .

- The model should facilitate the provision, as needed, for expert consultation related particularly to stroke prevention, but also home rehabilitation and addressing patient and carer problems .

- Telestroke should reduce the need for travel, particularly in remote areas .

- Ideally, a telestroke model should provide ongoing, updated guidelines for risk factor management to primary physicians in an accessible, user-friendly way .

- The system should be able to scientifically evaluate outcomes and cost, and to address the questions of effectiveness and economic implications .

- The system should be capable of 'flagging' patients at increased risk. This should be part of the bi-directional information feedback loop.

- Telestroke should allow for evaluation of health-related quality of life (HRQL). 
- There should be a standardised manner of reporting stroke outcome measures, risk outcome measures and resource utilisation across multiple telestroke systems to allow for comparison .

- The telestroke system should facilitate what is essentially case-management of stroke survivors in a bi- or multidirectional way (health provider to client and client to health provider).

In stroke survivors, the most appropriate and acceptable support for patients and their carers and families should take into account to the fact that most stroke patients are elderly, as are their carers, and the majority are not technologically proficient. This means that the model of telecommunication should be adaptable and appropriate to the needs of patients to ensure compliance and usage both in the short- and the long-term. It should be remembered that three role players need to be supported after discharge - i.e. patient, carer and primary care physician. Patients and care givers need psychological support, practical advice in addressing what is often a combination of risk factor management and adaptation to physical disability and social change. The primary care physician needs support and guidance in implementing the best practice guidelines for risk factors management and the treatment of post-stroke depression. An integrated care model should enhance the quality of care for stroke survivors by linking together domains such as education, surveillance, and detection of abnormalities. Such a telestroke model should contain discrete elements of intervention, so that depending on the social and economic setting, the appropriate intervention elements of the model can be selected.

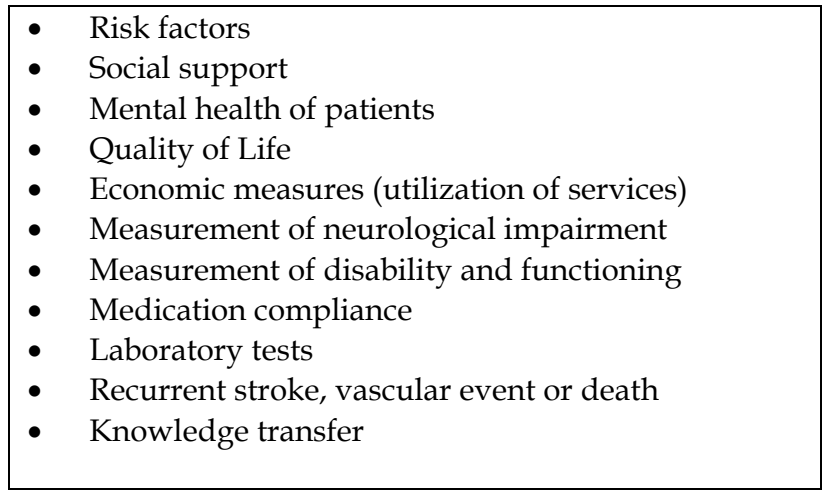

Box

\subsubsection{Implications for future developments in post-acute telestroke models}

A range of current telemedicine applications is potentially available for telestroke use. Many studies have shown the effectiveness of telemedicine for care management in a variety of chronic diseases such as for general health status monitoring (self-reported, or with homebased devices) with scheduled interventions such as nurse visit or GP consultation (video, telephone or physical attendance) ; medication compliance and modification, depending on symptoms and side-affects; and the early detection of deterioration of patients leading to 'just-in-time' interventions, preventing unnecessary admissions and healthcare costs . These are summarised in Table 3. 


\subsubsection{Significant implementation issues}

Telemedicine studies have shown various drawbacks which need to be considered . Many telehealth projects are neither successfully implemented, nor accepted despite being medically appropriate and technically viable. Cho et al. recently analysed the theoretical framework underpinning the implementation of a telestroke service (REACH) and a Swedish teleradiology service as models of care. Barriers to implementation were identified as insufficient planning of IT infrastructure, lack of long-term vision for sustainability, lack of contextual perspective, and poor communication with a lack of early involvement of important role players. Financial barriers contributing to difficulties with the diffusion of the project, if not foreseen and accounted for from early on, can lead to limited or aborted important implementation issues. Existing work practices have to be acknowledged, as IT innovations do not occur ex vacuo.

Organisational structures and various public and insurance funding changes may be needed to accommodate a different care regime that includes outreach through telemedicine. The sharing of patient health records between public and private health providers, medical and care professionals, and hospital and community centre care coordinators, leads to security, privacy and liability issues that need solving. More efficient use of communication dialogue and methods are needed to efficiently manage each patient interaction - especially as coordinator and medical case loads increase with greater use of telemedicine links to patients and carers. For example, there may need to be a differentiation between problemsolving, education and motivational dialogue from structured rehabilitation management tasks . In addition, an improved human/technology interface functionality is needed to take into account individual patient disabilities, time limitations and the technical skills of the carer. A flexibility of technology solutions should be adopted that allows for rates of obsolescence, local availability of supply, and support of hardware and software, especially as such telemedicine options are extended to different regions, states and countries. The current pilot studies of home-telemedicine do not provide sufficient evidence for full deployment scaling using major public health funding, although some have produced projected business cases and others are studying world wide practices. Telehealth models vary in systems architecture from two-way to three or more ways, with various implied control modes - nursing care coordinator or clinician (agency, hospital or clinic) or community. This impacts on the cost-effectiveness of bandwidth and computing intensive solutions, even though the component costs appear to be falling. This complexity makes the difficulty of technology selection all the greater.

\subsubsection{Economic evaluation of telestroke Implementations}

Although a specific search strategy for this aspect was not undertaken in this review, we noted that the resource implications of telestroke had been raised as an issue in several studies. To date, most studies have been designed to provide evidence for the technical feasibility of using current (telephone, videoconferencing) or new (Internet, Virtual Environment) technologies. Many of these studies are project-funded to address efficacy issues and full economic costs have not published. The economic impact of these telestroke systems is a critical area in need of more research. Costs involved in telestroke may include both set-up and operating costs, which have seldom been quantified. Moreover, many reported cost studies are based on such diverse technical, organisational and cost contexts that it would be difficult to draw conclusions in order to undertake a comprehensive costeffectiveness study. It has been noted that a lack of reimbursement for clinicians may be a 
major impediment to the use of telestroke. Such economic issues require further investigation .

The CADTH review was inconclusive as to whether telestroke was cost-effective and safe compared to face-to-face care. The authors highlighted the lack of standardised reporting that precluded comparisons between studies and best practice determination. This would also have implications for undertaking economic evaluation studies. Thus, the evidence related to costs and cost-effectiveness of telestroke appears limited. More recently, Ehlers et al reported that at one year, the net cost per patient treated with thrombolysis using telestroke compared to standard practice was $\$ 50,000$ and that at 2 years the intervention would save costs by reducing care and rehabilitation costs. However, the authors noted that although there may be potentially large savings associated with thrombolysis with alteplase delivered by telemedicine, the long-term calculations were uncertain. In another study designed to assess the cost-effectiveness of pharmacists giving advice via telephone to patients receiving a new medicine for a chronic condition (including stroke), the intervention was less costly and more effective than standard practice .

In 2010, Nelson et al. analysed the trade-off between short-term costs and long-term outcomes of telestroke in the Western States Stroke Consortium (WSSC). They studied a systematic method of comparing 2 or more interventions by measuring their costs and consequences (health outcomes) where the consequences of each are measured in common units related to the clinical objective of the interventions (e.g., life-years gained or qualityadjusted life-years). They show that telestroke was still cost-effective compared to usual care in the lifetime horizon model but not in the 90-day horizon model. However, there were certain limitations to the study. Their model did not consider stroke mimics, for example, which may also be the object of telestroke intervention. There are potential cost savings of not transferring such patients to tertiary care centres. Two new Canadian programmes have also been designed to address the economic and resource implications for telestroke, which may contribute further evidence to the debate on cost-effectiveness . Clearly, studies with long-term follow-up and consistent methodology are needed in this area.

\subsubsection{Need for well-designed studies}

Hersh et al. found that there were only a small number of well-designed telestroke studies in general, particularly in rural settings. There is a need for well-designed RCTs and longitudinal observational studies of clinical outcomes to demonstrate the effective use of telemedicine in stroke survivors discharged from hospital . Rigorously designed studies, such as those that have been recommended for telestroke in the acute phase, are needed .

\section{Conclusion}

\section{Future trends and recommendations}

There is clearly an urgent need, particularly in rural and underserved areas, to develop long-term management systems in stroke survivors that are both integrated and sustainable, serving all sections of the population, and with particular emphasis on the sustained implementation of best practice risk factor management. In these more remote areas of the world, the implementation of telemedicine may fill the gap in health care provision created by the high demand on healthcare provider time, the critical shortage of professional health services and geographical distance thereby progressing the ideals of the WHO contained in the Helsingborg Declaration . 
Ultimately, the long-term management of risk factors in stroke survivors rests with the primary care physician or other health practitioner acting as the final 'locus of control' for the patient. Unfortunately, despite the enormous calculated benefits flowing from the effective implementation of best practice recommendations, therapeutic inertia is common at primary care level. To address this, a combination of 'hub and spoke' case-management model (care coordinator, with multiple stroke survivors) and linear model (specialist, coordinator, carer, patient and primary care physician) could be advantageous. Telestroke may also minimise the inappropriate variations in medical practice. ICARUSS provides one telestroke model that is adaptable to various scenarios and integrates the roles of coordinator, primary care physician, specialist services and other telestroke support services in the care of both stroke survivor and caregiver. The model supports the implementation of secondary stroke prevention strategies and the detection of post-stroke depression. The focus is on providing care, support and specialist guidance to rural, remote or underserved areas in all fields related to the care of stroke survivors, in a model that continues to provide patients and carers with the face-to-face experience, but that also fully exploits the available modern technology options.

\section{Acknowledgement}

The RUN-FC network has been supported and funded by the French Health Ministry.

The ICARUSS study is supporte Ad by funding from the HCF HEALTH AND MEDICAL RESEARCH FOUNDATION. We would like to thank Melanie Cole for her editing assistance.

\section{References}

Adamson, J., A. Beswick, et al. (2004). "Is stroke the most common cause of disability?" Journal of stroke and cerebrovascular diseases : the official journal of National Stroke Association 13(4): 171-177.

AHA (2008). Heart Disease and stroke Statistics - 2008 Update. Dallas, TX, American Heart Association.

Audebert, H. (2006). "Telestroke: effective networking." Lancet neurology 5(3): 279-282.

Boter, H. (2004). "Multicenter randomized controlled trial of an outreach nursing support program for recently discharged stroke patients." Stroke; a journal of cerebral circulation 35(12): 2867-2872.

Bouffard, K. (1997). "Telemedicine: who's in charge?" Michigan medicine 96(9): 10-15; 17-19.

Brenner, D. A., R. M. Zweifler, et al. (2010). "Awareness, treatment, and control of vascular risk factors among stroke survivors." Journal of stroke and cerebrovascular diseases : the official journal of National Stroke Association 19(4): 311-320.

Broens, T. H., R. M. Huis in't Veld, et al. (2007). "Determinants of successful telemedicine implementations: a literature study." Journal of telemedicine and telecare 13(6): 303-309.

Buckley, K. M., B. Q. Tran, et al. (2004). "Receptiveness, use and acceptance of telehealth by caregivers of stroke patients in the home." Online journal of issues in nursing 9(3): 9 . 
Bulik, R. J. (2008). "Human factors in primary care telemedicine encounters." Journal of telemedicine and telecare 14(4): 169-172.

Cadilhac, D. A., R. C. Carter, et al. (2007). "Why invest in a national public health program for stroke? An example using Australian data to estimate the potential benefits and cost implications." Health policy 83(2-3): 287-294.

Camilo, O. and L. B. Goldstein (2003). "Statewide assessment of hospital-based stroke prevention and treatment services in North Carolina: changes over the last 5 years." Stroke; a journal of cerebral circulation 34(12): 2945-2950.

Champonnois, L., E. de Bustos, et al. (2010). RUN-FC (Réseau des Urgences Neurologiques en Franche-Comté). Symposium HAS-BMJ.

Cherry, J. C., K. Dryden, et al. (2003). "Opening a window of opportunity through technology and coordination: a multisite case study." Telemedicine journal and ehealth : the official journal of the American Telemedicine Association 9(3): 265-271.

Cho, S., E. V. Khasanshina, et al. (2007). "An analysis of business issues in a telestroke project." Journal of telemedicine and telecare 13(5): 257-262.

Croquelois, A. and J. Bogousslavsky (2006). "Risk awareness and knowledge of patients with stroke: results of a questionnaire survey 3 months after stroke." Journal of neurology, neurosurgery, and psychiatry 77(6): 726-728.

de Bustos, E., T. Moulin, et al. (2009). "Barriers, legal issues, limitations and ongoing questions in telemedicine applied to stroke." Cerebrovascular Diseases 27(Suppl 4): 36-39.

de Bustos, E. M., F. Vuillier, et al. (2009). "Telemedicine in stroke: organizing a network-rationale and baseline principles." Cerebrovascular Diseases 27(Suppl 4): 1-8.

Demaerschalk, B. M., H. M. Hwang, et al. (2010). "Cost analysis review of stroke centers, telestroke, and rt-PA." The American journal of managed care 16(7): 537-544.

Demiris, G., C. L. Shigaki, et al. (2005). "An evaluation framework for a rural home-based telerehabilitation network." Journal of medical systems 29(6): 595-603.

Dergalust, S., M. Rofail, et al. (2003). "The incidence of discontinuation of extended release dipyridamole/aspirin, clopidogrel and warfarin for the secondary prevention of stroke." Presented at the 55th American Academy of Neurology Annual Meeting; Honolulu, Hawaii. April 3.

Deshpande, A., S. Khoja, et al. (2010). "Telehealth for Acute Stroke Management (Telestroke): Systematic Review and Environmental Scan [Technology overview 37]." Ottawa: Canadian Agency for Drugs and Technologies in Health; 2008. 60(6): 991-999.

Dhamoon, M. S., R. R. Sciacca, et al. (2006). "Recurrent stroke and cardiac risks after first ischemic stroke: the Northern Manhattan Study." Neurology 66(5): 641-646.

Doze, S., J. Simpson, et al. (1999). "Evaluation of a telepsychiatry pilot project." Journal of telemedicine and telecare 5(1): 38-46.

Ehlers, L., W. M. Muskens, et al. (2008). "National use of thrombolysis with alteplase for acute ischaemic stroke via telemedicine in Denmark: a model of budgetary impact and cost effectiveness." CNS drugs 22(1): 73-81. 
Elliott, R. A., N. Barber, et al. (2008). "The cost effectiveness of a telephone-based pharmacy advisory service to improve adherence to newly prescribed medicines." Pharmacy world \& science : PWS 30(1): 17-23.

Goldstein, L. B. and P. M. Rothwell (2007). "Primary prevention and health services delivery." Stroke; a journal of cerebral circulation 38(2): 222-224.

Grant, J. S., T. R. Elliott, et al. (2002). "Telephone intervention with family caregivers of stroke survivors after rehabilitation." Stroke; a journal of cerebral circulation 33(8): 2060-2065.

Hachinski, V. (2002). "Stroke: the next 30 years." Stroke; a journal of cerebral circulation 33(1): $1-4$.

Hachinski, V., G. A. Donnan, et al. (2010). "Stroke: working toward a prioritized world agenda." Stroke; a journal of cerebral circulation 41(6): 1084-1099.

Hailey, D. and B. Crowe (2003). "A profile of success and failure in telehealth--evidence and opinion from the Success and Failures in Telehealth conferences." Journal of telemedicine and telecare 9 Suppl 2: S22-24.

Hardie, K., G. J. Hankey, et al. (2004). "Ten-year risk of first recurrent stroke and disability after first-ever stroke in the Perth Community Stroke Study." Stroke; a journal of cerebral circulation 35(3): 731-735.

Hebert, M. A. and B. Korabek (2004). "Stakeholder readiness for telehomecare: implications for implementation." Telemedicine journal and e-health : the official journal of the American Telemedicine Association 10(1): 85-92.

Hersh, W. R., D. H. Hickam, et al. (2006). "Telemedicine for the medicare population: update." Evidence report/technology assessment(131): 1-41.

Hess, D. C., S. Wang, et al. (2005). "REACH: clinical feasibility of a rural telestroke network." Stroke; a journal of cerebral circulation 36(9): 2018-2020.

Hjelm, N. M. (2005). "Benefits and drawbacks of telemedicine." Journal of telemedicine and telecare 11(2): 60-70.

Hopp, F., P. Whitten, et al. (2006). "Perspectives from the Veterans Health Administration about opportunities and barriers in telemedicine." J Telemed Telecare 12: 404-409.

Jencks, S. F., T. Cuerdon, et al. (2000). "Quality of medical care delivered to Medicare beneficiaries: A profile at state and national levels." JAMA : the journal of the American Medical Association 284(13): 1670-1676.

Joubert, J., L. Joubert, et al. (2008). "The positive effect of integrated care on depressive symptoms in stroke survivors." Cerebrovascular diseases 26(2): 199-205.

Joubert, J., L. B. Joubert, et al. (2009). "Telestroke in stroke survivors." Cerebrovascular diseases 27 Suppl 4: 28-35.

Joubert, J., L. F. Prentice, et al. (2008). "Stroke in rural areas and small communities." Stroke; a journal of cerebral circulation 39(6): 1920-1928.

Joubert, J., C. Reid, et al. (2006). "Risk factor management and depression post-stroke: the value of an integrated model of care." Journal of clinical neuroscience : official journal of the Neurosurgical Society of Australasia 13(1): 84-90. 
Jutras, A. (1959). "Teleroentgen diagnosis by means of video-tape recording." The American journal of roentgenology, radium therapy, and nuclear medicine 82: 1099-1102.

Kannel, W. B., P. A. Wolf, et al. (1970). "Epidemiologic assessment of the role of blood pressure in stroke. The Framingham study." JAMA : the journal of the American Medical Association 214(2): 301-310.

Kjellstrom, T., B. Norrving, et al. (2007). "Helsingborg Declaration 2006 on European stroke strategies." Cerebrovascular diseases 23(2-3): 231-241.

Kondalsamy-Chennakesavan, S., W. Hoy, et al. (2004). "Chronic disease surveillance and management in remote Aboriginal Australia: role of web-based applications." J Telemed Telecare 10: 101.

LaBresh, K. A., M. J. Reeves, et al. (2008). "Hospital treatment of patients with ischemic stroke or transient ischemic attack using the "Get With The Guidelines" program." Archives of internal medicine 168(4): 411-417.

LaMonte, M. P., M. N. Bahouth, et al. (2003). "Telemedicine for acute stroke: triumphs and pitfalls." Stroke; a journal of cerebral circulation 34(3): 725-728.

Lee, P. W., H. C. Schulberg, et al. (2007). "Concordance between the PHQ-9 and the HSCL20 in depressed primary care patients." Journal of affective disorders 99(1-3): 139145.

Levine, S. R. and M. Gorman (1999). "'Telestroke" : the application of telemedicine for stroke." Stroke; a journal of cerebral circulation 30(2): 464-469.

Levine, S. R. and K. M. McConnochie (2007). "Telemedicine for acute stroke: when virtual is as good as reality." Neurology 69(9): 819-820.

Lewis, M., J. Trypuc, et al. (2006). "Has Ontario's Stroke System really made a difference?" Healthcare quarterly 9(4): 50-59, 52.

Li, C., G. Engstrom, et al. (2008). "Long-term stroke prognosis in relation to medical prevention and lifestyle factors. A prospective population-based study." Cerebrovascular diseases 25(6): 526-532.

Lutz, B. J., N. R. Chumbler, et al. (2007). "Care coordination/home-telehealth for veterans with stroke and their caregivers: addressing an unmet need." Topics in stroke rehabilitation 14(2): 32-42.

Mackay, J. and G. A. Mensah (2004). "The atlas of heart disease and stroke." Geneva WHO.

Mayo, N. E., L. Nadeau, et al. (2008). "Bridging the gap: the effectiveness of teaming a stroke coordinator with patient's personal physician on the outcome of stroke." Age and ageing 37(1): 32-38.

Meade, B. J. and J. A. Dunbar (2004). "A virtual clinic: telemetric assessment and monitoring for rural and remote areas." Rural and remote health 4(3): 296.

Merino, J. G., S. U. Lattimore, et al. (2005). "Telephone assessment of stroke outcome is reliable." Stroke; a journal of cerebral circulation 36(2): 232-233.

Meschia, J. F., M. A. Lojacono, et al. (2004). "Reliability of the questionnaire for verifying stroke-free status." Cerebrovascular diseases 17(2-3): 218-223. 
Miley, M. L., B. M. Demaerschalk, et al. (2009). "The state of emergency stroke resources and care in rural Arizona: a platform for telemedicine." Telemedicine journal and ehealth : the official journal of the American Telemedicine Association 15(7): 691-699.

Misra, U. K., J. Kalita, et al. (2005). "Telemedicine in neurology: underutilized potential." Neurology India 53(1): 27-31.

Moulin, T., P. Decavel, et al. (2004). "Information technology (IT) support in the implementation of a stroke programme: the RUN-Stroke experiment." Cerebrovascular Diseases 17((supp 5)): 6.

Moulin, T., J. Joubert, et al. (2011). Telemedicine in Stroke: Potentials, Limitations and Ongoing Issues. Advances in Telemedicine: Applications in Various Medical Disciplines and Geographical Regions. Available from: http://www.intechopen.com/articles/show/title/telemedicine-in-strokepotentials-limitations-and-ongoing-issues, InTech.

Nelson, R., G. Saltzman, et al. (2010). Cost-Effectiveness of Telestroke for Ischemic Stroke: A Literature-Based Decision-Analytic Model Poster session presented at: American Heart Association / American Stroke Association International Stroke Conference, San Antonio, TX.

Noel, H. C., D. C. Vogel, et al. (2004). "Home telehealth reduces healthcare costs." Telemedicine journal and e-health : the official journal of the American Telemedicine Association 10(2): 170-183.

Ovbiagele, B., O. Drogan, et al. (2008). "Outpatient practice patterns after stroke hospitalization among neurologists." Stroke; a journal of cerebral circulation 39(6): 1850-1854.

Park, S. and L. H. Schwamm (2008). "Organizing regional stroke systems of care." Current opinion in neurology 21(1): 43-55.

Pierce, L. L., V. Steiner, et al. (2004). "Internet-based support for rural caregivers of persons with stroke shows promise." Rehabilitation nursing : the official journal of the Association of Rehabilitation Nurses 29(3): 95-99, 103.

Puskin, D. S. (2001). "Telemedicine: follow the money modalities." Online journal of issues in nursing 6(3): 2.

Rahimi, B. and V. Vimarlund (2007). "Methods to evaluate health information systems in healthcare settings: a literature review." Journal of medical systems 31(5): 397432.

Roine, R., A. Ohinmaa, et al. (2001). "Assessing telemedicine: a systematic review of the literature." CMAJ : Canadian Medical Association journal = journal de l'Association medicale canadienne 165(6): 765-771.

Rosamond, W., K. Flegal, et al. (2008). "Heart disease and stroke statistics--2008 update: a report from the American Heart Association Statistics Committee and Stroke Statistics Subcommittee." Circulation 117(4): e25-146.

Sato, S. and K. Ohta (1993). "[New network for emergency medical services of stroke with CT-picture teleradiology system]." Nippon rinsho. Japanese journal of clinical medicine 51 Suppl: 246-250.

Schneider, N. M. (2004). "Managing congestive heart failure using home telehealth." Home healthcare nurse 22(10): 719-722. 
Schwamm, L. H., H. J. Audebert, et al. (2009). "Recommendations for the implementation of telemedicine within stroke systems of care: a policy statement from the American Heart Association." Stroke; a journal of cerebral circulation 40(7): 2635-2660.

Schwamm, L. H., R. G. Holloway, et al. (2009). "A review of the evidence for the use of telemedicine within stroke systems of care: a scientific statement from the American Heart Association/American Stroke Association." Stroke; a journal of cerebral circulation 40(7): 2616-2634.

Schwamm, L. H., A. Pancioli, et al. (2005). "Recommendations for the establishment of stroke systems of care: recommendations from the American Stroke Association's Task Force on the Development of Stroke Systems." Stroke; a journal of cerebral circulation 36(3): 690-703.

SOTPSS (2004). Southeastern Ontario Telestroke Proposal Stroke Strategy.

Susman, E. (1997). "Telemedicine to give rural stroke victims fair chance of recovery with new treatment." Telemedicine Virtual Reality 2: 1-2.

Swanepoel de, W. and J. W. Hall (2010). "A systematic review of telehealth applications in audiology." Telemedicine journal and e-health : the official journal of the American Telemedicine Association 16(2): 181-200.

Tatlisumak, T., S. Soinila, et al. (2009). "Telestroke networking offers multiple benefits beyond thrombolysis." Cerebrovascular diseases 27 Suppl 4: 21-27.

Taylor, D. and L. Capamagian (2007). "Experience with planned and coordinated care using telemedicine." J Telemed Telecare 13: 86-87.

Taylor, P. (2005). "Evaluating telemedicine systems and services." Journal of telemedicine and telecare 11(4): 167-177.

Touze, E., J. Coste, et al. (2008). "Importance of in-hospital initiation of therapies and therapeutic inertia in secondary stroke prevention: IMplementation of Prevention After a Cerebrovascular evenT (IMPACT) Study." Stroke; a journal of cerebral circulation 39(6): 1834-1843.

Tran, B. Q., K. M. Buckley, et al. (2002). "Selection \& use of telehealth technology in support of homebound caregivers of stroke patients." Caring : National Association for Home Care magazine 21(3): 16-21.

Wang, D. Z. (2003). "Editorial comment-- telemedicine: the solution to provide rural stroke coverage and the answer to the shortage of stroke neurologists and radiologists." Stroke; a journal of cerebral circulation 34(12): 2957.

Webb, D. and P. Williams (2006). Telemedicine and the Digital Door Doctor. 4th Australian Information Security Management Conference, Edith Cowan University, Perth, W. Australia, School of Computer and Information Science, Edith Cowan University, Perth, Western Australia.

Whisnant, J. P. (1997). "Modeling of risk factors for ischemic stroke. The Willis Lecture." Stroke; a journal of cerebral circulation 28(9): 1840-1844.

Whitten, P. S., F. S. Mair, et al. (2002). "Systematic review of cost effectiveness studies of telemedicine interventions." BMJ 324(7351): 1434-1437.

WHO. (2011). "Fact Sheet $N^{\circ} 311$, Obesity and Overweight." Retrieved 06 May, 2011, from http://www.who.int/mediacentre/factsheets/fs311/en/index.html. 
WHO. (2011). "Fact Sheet $\mathrm{N}^{\circ}$ 312, Diabetes." Retrieved 06 May, 2011, from http://www.who.int/mediacentre/factsheets/fs312/en/index.html.

Wiborg, A. and B. Widder (2003). "Teleneurology to improve stroke care in rural areas: The Telemedicine in Stroke in Swabia (TESS) Project." Stroke; a journal of cerebral circulation 34(12): 2951-2956.

Williams, L. S., E. J. Brizendine, et al. (2005). "Performance of the PHQ-9 as a screening tool for depression after stroke." Stroke; a journal of cerebral circulation 36(3): 635-638.

Winters, J. Telerehabilitation Applications. BIEN 167 Module 3 Telerehabilitation. Milwaukee, Wisconsin, Marquette University.

Wittson, C. L., D. C. Affleck, et al. (1961). "Two-way television in group therapy." Mental hospitals 12: 22-23.

Yusuf, S. (2002). "Two decades of progress in preventing vascular disease." Lancet 360(9326): 2-3.

Zerwic, J., S. Y. Hwang, et al. (2007). "Interpretation of symptoms and delay in seeking treatment by patients who have had a stroke: exploratory study." Heart \& lung : the journal of critical care 36(1): 25-34. 


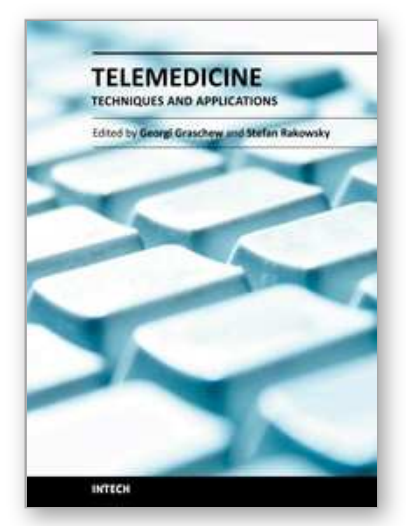

\author{
Telemedicine Techniques and Applications \\ Edited by Prof. Georgi Graschew
}

ISBN 978-953-307-354-5

Hard cover, 514 pages

Publisher InTech

Published online 20, June, 2011

Published in print edition June, 2011

Telemedicine is a rapidly evolving field as new technologies are implemented for example for the development of wireless sensors, quality data transmission. Using the Internet applications such as counseling, clinical consultation support and home care monitoring and management are more and more realized, which improves access to high level medical care in underserved areas. The 23 chapters of this book present manifold examples of telemedicine treating both theoretical and practical foundations and application scenarios.

\title{
How to reference
}

In order to correctly reference this scholarly work, feel free to copy and paste the following:

Joubert J, Medeiros de Bustos E, Decavel P, Chopard JL, Joubert LB and Moulin T (2011). Telestroke for the Long-term Management of Risk Factors in Stroke Survivors, Telemedicine Techniques and Applications, Prof. Georgi Graschew (Ed.), ISBN: 978-953-307-354-5, InTech, Available from:

http://www.intechopen.com/books/telemedicine-techniques-and-applications/telestroke-for-the-long-termmanagement-of-risk-factors-in-stroke-survivors

\section{INTECH}

open science | open minds

\section{InTech Europe}

University Campus STeP Ri Slavka Krautzeka 83/A 51000 Rijeka, Croatia Phone: +385 (51) 770447

Fax: +385 (51) 686166 www.intechopen.com

\section{InTech China}

Unit 405, Office Block, Hotel Equatorial Shanghai No.65, Yan An Road (West), Shanghai, 200040, China 中国上海市延安西路65号上海国际贵都大饭店办公楼405单元 Phone: +86-21-62489820

Fax: +86-21-62489821 
(C) 2011 The Author(s). Licensee IntechOpen. This chapter is distributed under the terms of the Creative Commons Attribution-NonCommercialShareAlike-3.0 License, which permits use, distribution and reproduction for non-commercial purposes, provided the original is properly cited and derivative works building on this content are distributed under the same license. 